\title{
A CASE OF UNILATERAL PULMONARY EMPHYSEMA
}

\author{
BY \\ PAUL R. SWYER AND G. C. W. JAMES \\ From Warwick Hospital
}

(RECEIVED FOR PUBLICATION AUGUST 18, 1952)

It is not uncommon to see unilateral pulmonary emphysema compensating for lobar collapse, or as a mechanical result of valvular obstruction of a bronchus. The clinical details of a case where neither of these factors was present, with a pathological report on the resected lung, form the subject of this paper.

\section{Clinical Report}

The patient was a boy aged 6 years who came under observation after an attack of acute bronchitis in September, 1949. At the ages of 5 weeks, 2 years, and 3 years he had had bronchopneumonia, and since the age of 3 years he had been subject to recurrent attacks of bronchitis, which affected mainly the right lung.

The boy was mentally normally developed, but slightly below standard height and weight for his age. Slight clubbing of the fingers was present. Chest expansion was poor on both sides, but more so on the right. Air entry on the right side was diminished with scattered

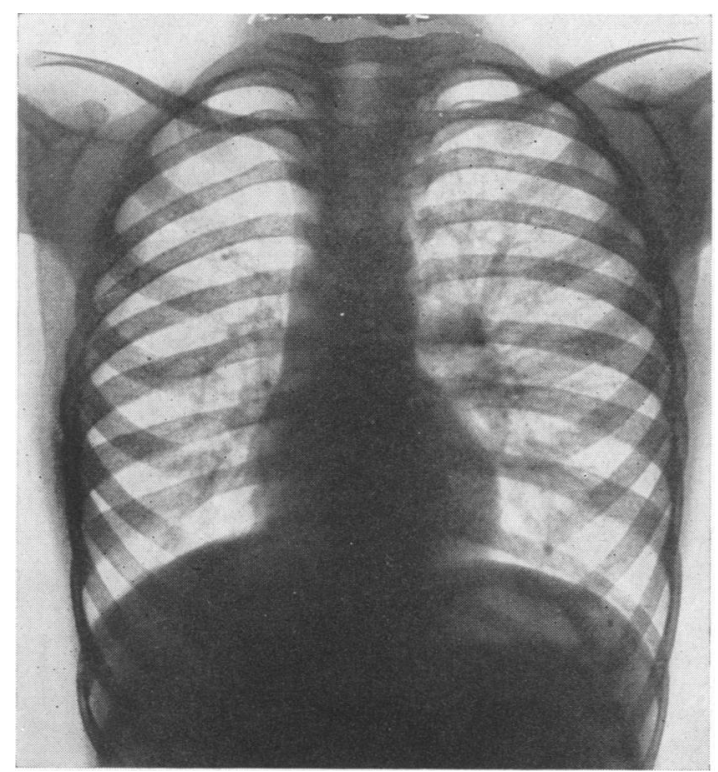

FIG. 1.-Postero-anterior radiograph showing relative transradiancy of the right lung. The right hilar vascular shadow is smaller and the left larger than normal. crepitations throughout, and there were a few persistent crepitations at the left base. Other systems were apparently normal.

A radiograph of the chest showed relative transradiancy of the right lung field compared with the left, with considerable decrease of vascular markings. The heart was slightly displaced to the right. The right hemithorax and lung were smaller than the left despite the increased transradiancy on the right (Fig. 1). Fluoroscopy showed movement of the heart to the right on inspiration and restricted excursion of the right diaphragm.

Bronchography showed on the left side only slight dilatation of the posterior basic segmental bronchus of the lower lobe, and on the right a peculiar appearance because the peripheral bronchi failed to fill, with a sharp line of demarcation between the proximal filled and the peripheral unfilled parts (Figs. 2 and 3). Bronchoscopy showed that the main bronchi were normal with very little secretion present. Angiocardiography showed a normal heart with a right pulmonary artery much diminished in calibre, and confirmed the poor

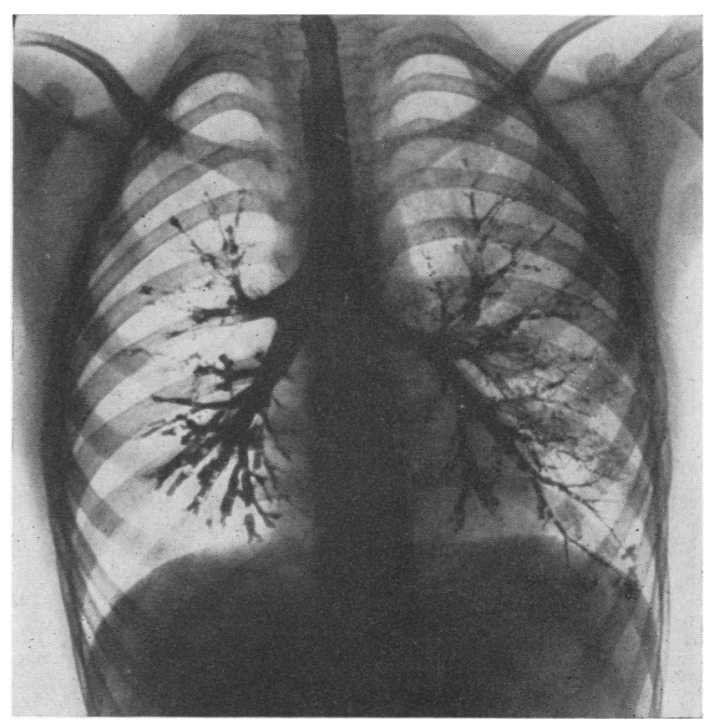

FIG. 2.-Postero-anterior bronchogram. Note that the peripheral divisions of the right bronchial tree compared with the left have not filled. 
vascular filling of the right lung in contrast to the overfull left side, which had been suspected from the appearance of the radiograph (Fig. 4). In view of these findings demonstrating a small, functionally deficient lung, prone to recurrent infections, a right pneumonectomy was advised.

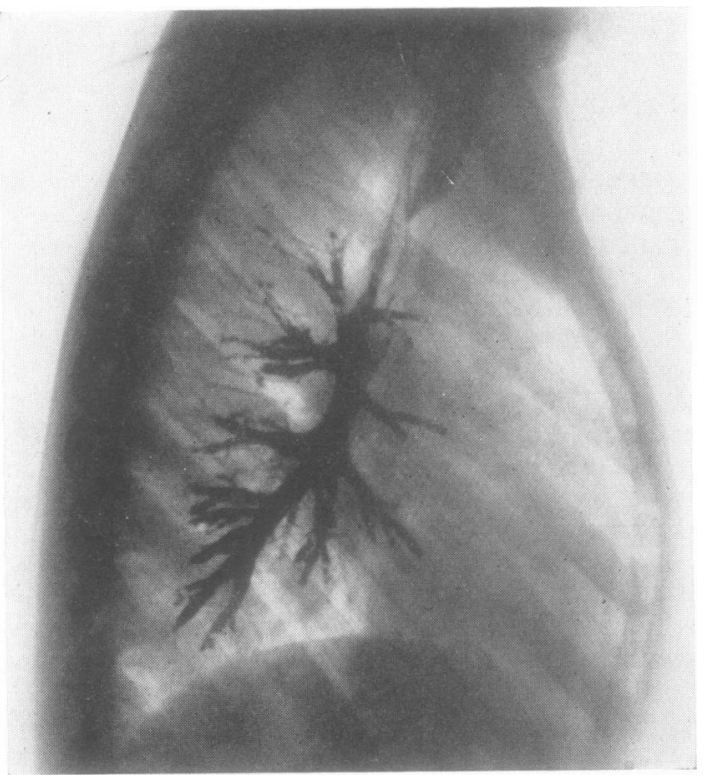

FIG. 3.-Right lateral bronchogram showing normal distribution of main bronchi but failure of peripheral filling.

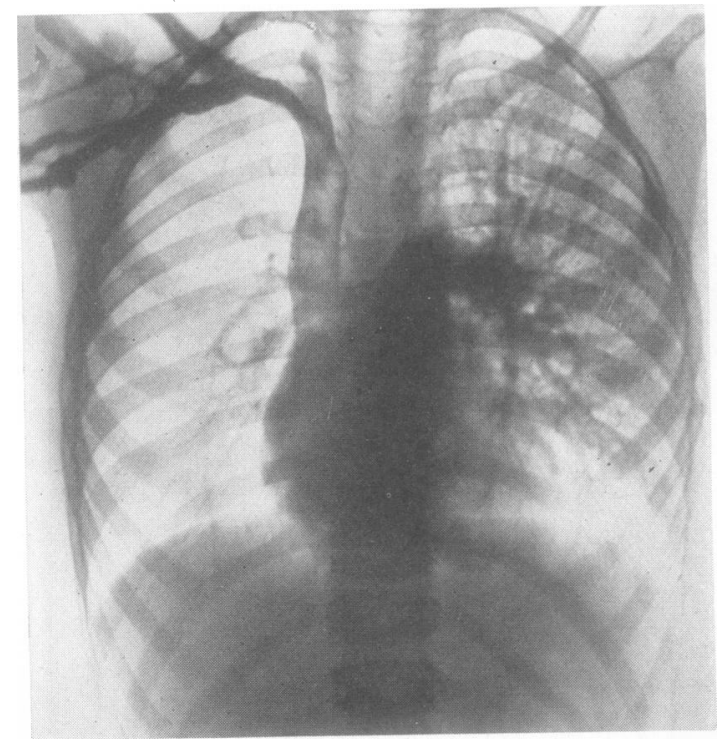

FIG. 4.-Angiogram 3 seconds after injection showing the contrast between the under-filled right pulmonary artery and the overfilled left side.
Right dissection pneumonectomy was performed on January 26, 1950, by Mr. J. Leigh Collis. On opening the chest the pleura was free, and it was noticed that carbon pigmentation was present on the anterior part of the right upper lobe only and that the horizontal fissure was absent. Surprisingly the right pulmonary artery was of larger calibre than the angiograms suggested. It was also noticed that the pulmonary veins were larger than normal and that the right bronchial arteries were within normal limits. The post-operative course was uneventful.

\section{Pathological REPORT}

RIGHT LUNG: MACROSCOPIC.-The fissure between the upper and middle lobes was absent. The cranial one-third was blackish and the remainder pink. Dissection of the bronchial tree showed normal ramifications.

The cut stump of the pulmonary artery was about $7 \mathrm{~mm}$. in diameter, dividing almost at once into two branches $5 \mathrm{~mm}$. in diameter.

A group of cystic cavities $5-10 \mathrm{~mm}$. in diameter was present at the apex of the upper lobe. No macroscopic cysts were seen in the lower lobe, which appeared emphysematous.

MICROsCOPIC.-There were many cystic spaces of varying diameters. The larger were lined by ciliated columnar epithelium with plates of cartilage, abundant plain muscle fibres, mucous glands, but rather scanty elastic fibres in their walls. Some had only a partial epithelial lining and resembled dilated respiratory bronchioles. Some alveoli were collapsed and others emphysematous. Fairly numerous lymphadenoid nodules were seen in relation to bronchi which were dilated, some of which showed chronic inflammatory changes in their walls (Figs. 5 and 6).

One of the most striking features was the widespread obliteration of peripheral lung capillaries in the walls of emphysematous alveoli (Fig. 7).

\section{Discussion}

Clinically, there were recurrent attacks of bronchitis mainly confined to the right side of the $\mathrm{O}$ chest. The small size of the right lung and the normal bronchoscopic appearances showed that the condition was not emphysema due to obstruction in the main bronchi. Similarly emphysema compensating for a tight segmental atelectasis was excluded by the normal distribution of the main $N$ bronchi shown by bronchography. The clinical and radiological findings, supported by the angiocardiograms, made us conclude that irreversible changes in the lung, possibly secondary to hypoplasia of the right pulmonary artery, were pro- $T$ ducing an almost functionless lung. The clinical

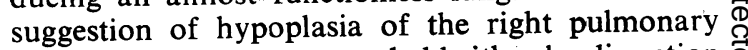
artery, however, was not upheld either by dissection $\mathbb{\mathbb { D }}$ of the pulmonary artery at operation, or by the examination of the lung, which showed that the 
pulmonary artery was only slightly diminished in size and that the anatomical distribution was normal.

Pathological study of the resected lung suggested cystic disease of the lung with secondary diminution in the size of the pulmonary artery. Dotter

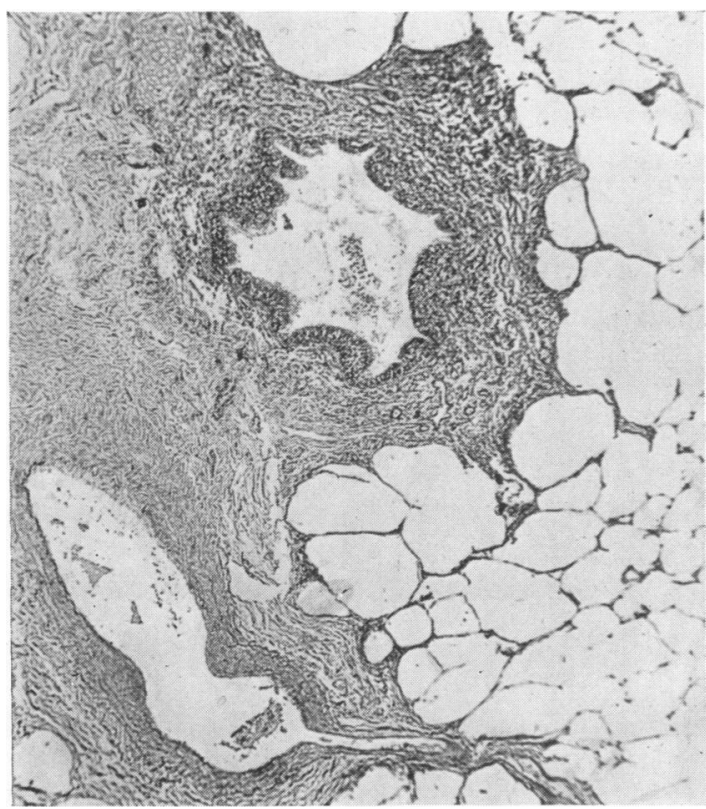

FIG. 5.-Peribronchial fibrosis and lymphadenoid nodule of the right lower lobe. Van Gieson stain, $\times 35$.

and Steinberg (1949) and Dotter (1950) in their series of angiocardiograms have noted a similar diminution in size of the pulmonary artery secondary to widespread unilateral lung disease. The origin of the lung condition in our case is uncertain. We think that the cystic condition in the lung was more likely to be acquired than congenital. Microscopically there was evidence of considerable bronchitis and bronchiolitis, both past and present, and the emphysema may well have been secondary to infection and peripheral obstruction in the smaller bronchi. Although it is usual in emphysematous lungs for the main pulmonary arterial branches to dilate rather than to contract in size, in our case the more normal left lung may have offered an alternative route of less resistance for the pulmonary arterial blood.

The alternative is to assume that the pulmonary artery was congenitally abnormal and that the lung dysplasia was secondary to the resultant diminished blood flow. This seems unlikely in view of the normal macroscopic and microscopic appearances of the pulmonary artery. But if the causative factor was in fact not congenital, it must have been operative from a very early age, in view of the relative absence of carbon pigmentation of the affected lung in a child who had spent all his life in an industrial coalmining district. The history

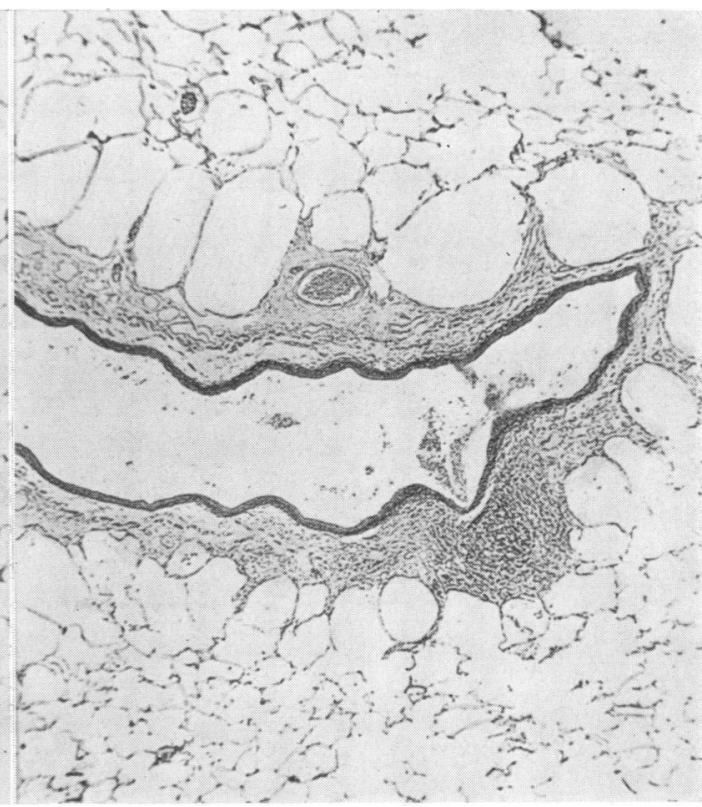

FIG. 6.-Small bronchus of the right upper lobe. Some of the surrounding alveoli are dilated and some collapsed. Haematoxyiin and eosin, $\times 30$.

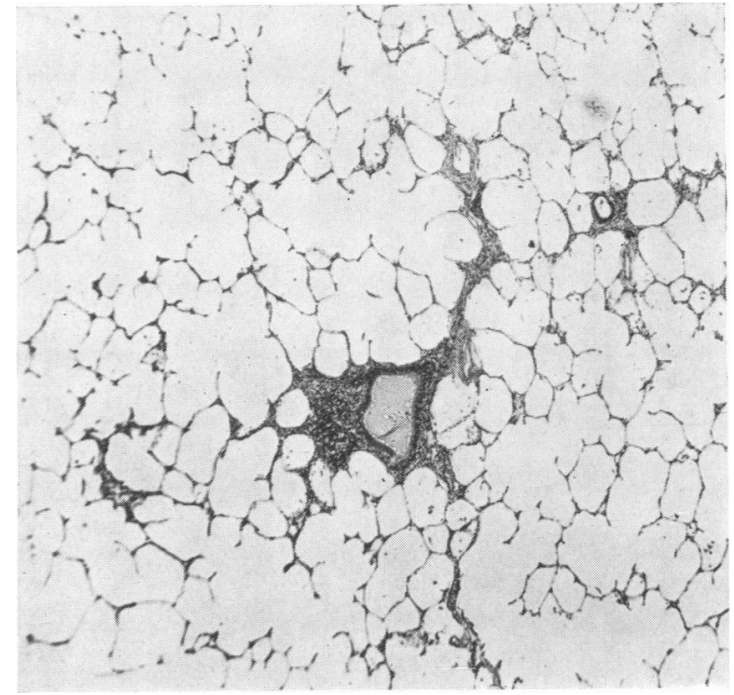

FIG. 7.-Bronchiole of the right lower lobe containing secretion surrounded by emphysematous alveoli with thin walls and few capillaries. Haematoxylin and eosin. $\times 35$. 
of pneumonia at the age of 5 weeks may be significant in this connexion.

We therefore conclude that our case showed functional insufficiency of the right pulmonary artery secondary to widespread lung disease of uncertain, but possibly of acquired, origin.

\section{SUMMARY}

A case is reported of unilateral pulmonary emphysema, with secondary deficiency of blood supply.
Right pneumonectomy was performed successfully.

The emphysematous condition is considered to be acquired in origin.

We wish to thank Dr. M. E. MacGregor and Mr. J. Leigh Collis for their help and permission to publish $\mathbb{\complement}$ this case; Dr. J. G. Scadding, who saw the case in ô consultation, for his help and advice; Dr. H. S. Baar for the pathological report; and Dr. Glasgow for the angiogram.

\section{REFERENCES} Dotter, C. T. (1950). Personal communication.
and Steinberg, I. (1949). J. Amer. med. Ass., 139, 566. 